\title{
Relato de experiência dos atendimentos de enfermagem em triagem para o diagnóstico da COVID-19 em profissionais da saúde
}

RESUMO | Objetivo: Descrever as dificuldades relatadas pelos profissionais de saúde perante a assistência a pacientes suspeitos ou confirmados da COVID-19, durante um atendimento em triagem para realização de exame. Método: Trata-se de um relato de experiência dos atendimentos em triagem de enfermagem à profissionais de saúde para coleta de amostras para o diagnóstico da COVID-19, entre abril a julho de 2020, em uma universidade pública da região central do Brasil. Resultados: As dificuldades reportadas foram: acesso limitado aos Equipamentos de Proteção Individual nos ambientes de trabalho; acesso restrito a testagem diagnóstica para COVID-19 e pouco conhecimento sobre a diferenciação e finalidade dos testes. Conclusão: A atuação da enfermagem aos profissionais da saúde na pandemia é de extrema importância. É relevante abordagens estratégicas de órgãos governamentais e de instituições de saúde acerca de capacitação para os profissionais da saúde e acesso aos equipamentos necessários para a saúde do trabalhador.

Palavras-chaves: Infecções por Coronavirus; Enfermagem em Saúde Comunitária; Serviços de Saúde.

ABSTRACT | Objective: To describe the difficulties reported by health professionals during the screening service, given the difficulties in assisting suspected or confirmed patients at COVID-19. Method: This is an experience report of the care provided in nursing screening to health professionals to collect samples for the diagnosis of COVID-19, between April and July 2020, at a public university in central Brazil. Results: The difficulties reported were: limited access to Personal Protective Equipment in the workplace; restricted access to diagnostic testing for COVID-19 and poor knowledge about the differentiation and purpose of the tests. Conclusion: The performance of nursing to health professionals in the pandemic is extremely important. Strategic approaches by government agencies and health institutions regarding training for health professionals and access to equipment necessary for workers' health are relevant.

Keywords: Coronavirus Infections; Community Health Nursing; Health Services.

RESUMEN | Objetivo: Describir las dificultades reportadas por los profesionales de la salud durante el servicio de cribado, dadas las dificultades para atender a pacientes sospechosos o confirmados en COVID-19. Método: Se trata de un informe de experiencia de la atención brindada en el cribado de enfermería a profesionales de la salud para recolectar muestras para el diagnóstico de COVID-19, entre abril y julio de 2020, en una universidad pública del centro de Brasil. Resultados: Las dificultades reportadas fueron: acceso limitado a Equipo de Protección Personal en el lugar de trabajo; acceso restringido a las pruebas de diagnóstico para COVID-19 y poco conocimiento sobre la diferenciación y el propósito de las pruebas. Conclusión: El desempeño de la enfermería a los profesionales de la salud en la pandemia es de suma importancia. Los enfoques estratégicos de las agencias gubernamentales y las instituciones de salud con respecto a la capacitación de los profesionales de la salud y el acceso a los equipos necesarios para la salud de los trabajadores son relevantes.

Palavras claves: Infecciones por Coronavirus; Enfermería en Salud Comunitaria; Servicios de Salud.

Cíntia Maria Tanure Bacelar Antunes

Enfermeira. Mestre em Enfermagem pela UNB. Enfermeira Secretaria se Saúde do DF.

ORCID: 0000-0001-6699-7681

\section{Cristiana da Costa Luciano}

Enfermeira. Doutora em Enfermagem - Professora Efetiva na Faculdade de Enfermagem da Universidade Federal de Goiás.

ORCID: 0000-0002-2309-3719

\section{Julyana Cândido Bahia}

Enfermeira. Doutoranda em Enfermagem (FEN/UFG), mestre em enfermagem (FEN/UFG), especialista em enfermagem obstétrica e neonatal. Enfermeira obstétrica no Hospital e Maternidade Dona Iris. Goiânia (GO).

ORCID: 0000-0001-5027-6652

\section{Rayssa Maria de Araújo Ferreira Paula Bastos}

Graduacao em enfermagem pela UFG. Enfermeira do serviço de telemonitoramento na central humanizada da COVID-19. ORCID: 0000-0003-1872-3584

Recebido em: 30/07/2020 Aprovado em: 24/08/2020
INTRODUÇÃO

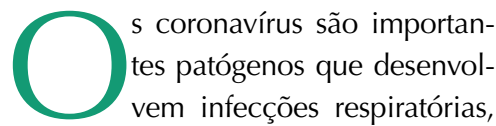
gastrointestinais, hepáticas e no sistema nervoso central. O coronavírus pertence a família coronaviridae da ordem nidovirales e as subfamílias; alfacoranvírus, betacoronavírus, deltacoronavírus e gamacoronavírus. No final do ano de 2019, na província de Wuhan, na China, foi detectado o novo coronavírus, da subfamília betacoronavírus que é responsável pela Síndrome Respiratória Aguda Grave (SARS), denominado como vírus SARS-CoV-2, o qual desenvolve a doença COVID-191,2. Em 11 março de 2020 a Organização 
Mundial de Saúde (OMS) considerou a COVID-19 uma pandemia ${ }^{3}$.

A disseminação do SARS-CoV-2 ocorre de pessoa para pessoa por meio das vias respiratórias, por gotículas, através da tosse ou espirro, por aerossóis, através de procedimentos como entubação orotraqueal, aspiração de secreção e outros. A disseminação por contato ocorre por meio do contato com a pessoa infectada e com superfície contaminada pelo vírus $^{1,2,3}$. Desta forma, é essencial que os profissionais da saúde na linha de frente da pandemia da COVID-19 estejam amparados com os Equipamentos de Proteção Individual (EPI) necessário para cada assistência a ser ofertada ${ }^{3}$.

A doença da COVID-19 apresenta um conhecimento científico restrito, relativo à sua abordagem e diversas manifestações clínicas inespecíficas que podem incluir tosse, febre $\geq 37,8^{\circ} \mathrm{C}$, dispneia, mialgias, fadiga ou cansaço, sintomas gastrointestinais como diarreia, anosmia (perda do olfato) ou hiposmia (diminuição do olfato), ageusia (perda do sentido do paladar), dor de garganta, cefaleia e calafrios ${ }^{2,3}$.

No decorrer da pandemia, evidências apontaram manifestações clínicas extrapulmonares relacionadas ao SARS-CoV-2, como alterações neurológicas, cardíacas, sistema vascular, alterações renais, hepáticas, endócrinas, gastrointestinais e alterações dermatológicas ${ }^{3}$. A OMS aborda que, a maioria dos pacientes com COVID-19 diagnosticada podem ser assintomáticos e oligossintomáticos ${ }^{3}$.

Os pacientes que apresentam quadro de manifestações clínicas sugestivas da COVID-19, além de exames de imagem típicas da pneumonia viral tais como; radiografia do tórax e Tomografia Computorizada (TC) de tórax é indicado a investigação para diagnóstico da doença ${ }^{1,2,3}$.

Para a confirmação diagnóstica da COVID-19 ocorre por meio de testes de detecção do SARS-CoV-2 por biologia molecular em Reação em Cadeia da Polimerase em Tempo Real (RT-PCR), (do inglês, Reverse transcription polymerase chain reaction), que detectam o RNA do vírus em secreção nasofaríngea e/ou orofaríngea e testes rápidos que são testes sorológicos validados capazes de detectar a presença de anticorpos anti-SARS-CoV-2 IgM e IgG em amostras de plasma sanguíneo ${ }^{3,4,5,6,7}$.

Neste contexto, a disseminação do vírus ocorreu em vários países e o profissional enfermeiro tem desempenhado papel vital como parte integrante aos atendimentos de saúde a população suspeita ou confirmada da COVID-19 nos mais diversos níveis de assistência, atuando no cuidado em saúde pública na prevenção e controle de infecções. A enfermagem tem apresentado como um grupo profissional de maior contaminação pelo SARS-CoV-2, devido à insuficiência de dispositivos para proteção, sobrecarga de trabalho, falta de produto para saúde, gerando insatisfação do cuidado, sentimento de angústia, ansiedade, pressão psicológica e estresse laboral ${ }^{4,5}$.

Contudo, salientamos em escrever este relato de experiência para externar com a comunidade científica os principais enfrentamentos vivenciados pelos profissionais da enfermagem na prática diária da triagem (acolhimento) à profissionais de saúde no momento que antecede a coleta de exames para diagnóstico da COVID-19.

Diante disso, o objetivo do relato de experiência é descrever as dificuldades relatadas pelos profissionais de saúde durante o atendimento em triagem, perante as dificuldades da assistência à pacientes suspeitos ou confirmados da COVID-19.

\section{MÉTODO}

Trata-se de um relato de experiência sobre a atuação da enfermagem em atendimentos à profissionais de saúde na Coleta de amostras para diagnóstico da COVID-19 de uma universidade pública da região central do Brasil, entre abril a julho de 2020. A coleta de amostras para diagnóstico da COVID-19 em profissionais da saúde apresentava o enfoque em ampliar o diagnóstico destes profissionais e minimizar a disseminação dos SARS-CoV-2.
O ambiente destinado para a coleta de amostras desenvolvia aplicação direta dos protocolos publicados pelo Ministério da Saúde, Agência Nacional de Vigilância Sanitária e Center Disease Control na testagem diagnóstica dos profissionais da saúde sintomáticos para a COVID-19.

A testagem diagnóstica para a $\mathrm{CO}$ VID-19 era realizada em ambiente aberto e arejado, e os exames eram por meio da RT-PCR e teste rápido, a depender da sintomatologia no momento do atendimento desses profissionais.

Inicialmente os profissionais da saúde com sintomas eram triados por professores enfermeiros e estudantes de enfermagem, para aplicação de um questionário semiestruturado de dados sociodemográficos, após, os professores médicos e estudantes de medicina, analisavam os dados do paciente para determinar qual o exame diagnóstico ideal a ser realizado. Posteriormente, os professores enfermeiros e estudantes de enfermagem realizavam a coleta das amostras dos pacientes da categoria profissionais da saúde.

$\mathrm{O}$ atendimento da enfermagem desenvolvido no espaço para coleta de amostra era realizado por professores e estudantes de enfermagem do último ano da graduação em enfermagem e tinha o propósito de realizar o acolhimento do profissional da saúde sintomático, escuta ativa, abordagem dos aspectos relativos as características sociodemográficas, clínicas, histórico de realização de testes anteriores para COVID-19, investigação do início dos sinais e sintomas e suas características, assim como aferição dos sinais vitais, saturação de oxigênio, por meio da oximetria de pulso, temperatura, frequência cardíaca, respiratória e posteriormente a coleta de amostras para o exame diagnóstico.

A média de duração do atendimento da enfermagem aos profissionais da saúde sintomático ocorria entre 15 a 20 minutos incluindo a aplicabilidade de um questionário semiestruturado para nortear a assistência. Todas as informações obtidas para discussão e reflexão 
nesse relato de experiência foram expressas pelos profissionais da saúde de forma espontânea durante os atendimentos de identificação e aplicação do questionário e no momento da coleta de amostra.

Todas as medidas de segurança e proteção estruturadas nas recomendações do Ministério da Saúde 8,9 e na OMS 10 foram tomadas para evitar a disseminação e a transmissão do SARS-CoV-2 no ambiente de trabalho.

\section{RESULTADOS}

$\mathrm{O}$ atendimento de enfermagem desenvolvido durante a coleta de amostras oportunizou um momento de acolhimento, por meio de abordagem holística e humanizada, a fim de identificar o exame ideal para o diagnóstico da COVID-19 aos profissionais da saúde.

Antes de iniciar a coleta das amostras, realizamos a identificação dos dados sociodemográficos e clínicos dos profissionais da saúde, para posteriormente destiná-lo a testagem para COVID-19, seguindo um fluxo unidirecional. O primeiro atendimento era realizado pela enfermagem, em seguida o atendimento médico e finalmente à realização da coleta de amostra para a testagem definida em protocolo específico, embasado nas diretrizes governamentais.

Durante o atendimento de enfermagem evidenciamos a necessidade dos pacientes da categoria profissionais da saúde expressarem seus sentimentos além de responder apenas às perguntas realizadas, em certas ocasiões o mesmo se estendia em virtude dessa necessidade.

Neste momento, do atendimento de enfermagem em que os pacientes que eram profissionais da saúde sintomáticos expressavam suas dificuldades enfrentadas no momento da pandemia. As dificuldades mais evidentes que foram referidas pelos profissionais da saúde durante o atendimento de enfermagem, foram categorizamos em três eixos principais: 1) acesso limitado aos EPIs nos ambientes de trabalho; 2) acesso restrito à testagem diagnóstica para COVID-19; e 3) pouco conhecimento sobre a diferenciação e finalidade dos testes para COVID-19.

Durante o atendimento de enfermagem foi referido por muitos profissionais da saúde a dificuldade dos gestores dos serviços em disponibilizarem os EPIs em quantidade suficiente e de qualidade, alguns referiram lesões na face por conta

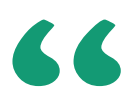

Antes de iniciar a coleta das amostras, realizamos a identificação dos dados sociodemográficos e clínicos dos profissionais da saúde, para posteriormente destiná-lo a testagem para COVID-19...

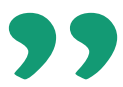

do uso de máscaras N95/PFF2 com adaptações inadequadas, que apresentam excessiva pressão sobre a face causando cefaleias durante o turno de trabalho e até mesmo lesões por pressão.

Em relação a realização dos testes para diagnóstico como o teste rápido e o PCR, os profissionais relataram insa- tisfação com a desatenção/ descaso dos locais de trabalho que não disponibilizaram testes de diagnóstico mesmo frente a quadro sintomatológico compatível com suspeita de contaminação por SARS-CoV-2 ou na ocorrência de membro da equipe apresentar resultado reagente para o novo coronavírus. Este tipo de relato foi descrito por profissionais da saúde da rede de atenção pública e principalmente por enfermeiros e técnicos da rede de atenção privada, com queixas de desconsideração pela dignidade da vida das pessoas que estavam na "linha de frente" da pandemia da COVID-19.

Os testes para diagnóstico eram indicados de acordo com a data transcorrida do início dos sintomas, sendo nos primeiros dias o RT-PCR e a partir do $7^{\circ}$ dia o teste rápido. Em alguns atendimentos ocorreram questionamentos prévios durante o processo de atendimento quanto ao teste a ser realizado, com contestação do protocolo adotado, demonstrando desconhecimento da correta finalidade de cada teste. Este fato demonstra que, mesmo com abundância de orientações sobre diagnóstico, inclusive em guias oficiais nacionais, que deveriam ser de conhecimento por profissionais da saúde que estão lidando cotidianamente com essa realidade, a desinformação é um fator conflitante para a equipe que busca atendimento.

\section{DISCUSSÃO}

Os EPIs especialmente no momento atual de pandemia tornaram-se aliados dos profissionais da saúde para garantir a proteção contra as partículas virais presentes em superfícies e dispersas ao ar, minimizando assim a disseminação e contaminação por meio do SARS-CoV-2 $2^{3-5}$. Portanto o uso correto dos EPIs bem como a integridade dos equipamentos favorece na prevenção e controle da infecção e na qualidade de vida dos profissionais da saúde que estão diariamente no enfrentamento e combate a disseminação do novo coronavírus no ambiente de trabalho ${ }^{3-5}$. 
Sendo assim, compõem os EPls utilizados na prática nos ambientes para saúde: gorro, luvas de procedimento, avental de manga longa impermeável, máscara cirúrgica, máscara N95 ou PFF2, propé, óculos de proteção e protetor facial (do inglês; face shield). Além desses EPIs há insumos que não podem faltar para garantir a segurança do trabaIhador tais como álcool em gel a 70\%, água e sabão para higiene das mãos e papel toalha ${ }^{10}$.

Além disso, muitos profissionais da saúde abordavam que a escassez de EPI era uma problemática global e que trabalhavam em ambientes extremamente insalubres apenas com máscaras cirúrgicas, contrariando as recomendações governamentais vigentes ${ }^{8,9,10}$, haja vista que os gestores não Ihes ofereciam os EPIs apropriado aumentando o risco de exposição ao vírus10. Estudo realizado na América Latina com profissionais da saúde revelou que $43,9 \%$ dos trabalhadores não tiveram acesso as máscaras do tipo N95 e 67,6\% aos protetores faciais revelando a magnitude dessa problemática ${ }^{11,12}$.

Recomendações internacionais des- tacam que os empregadores dos profissionais de saúde devem providenciar medidas de segurança apropriadas para segurança pessoal e aconselhar os trabalhadores a manter isolamento quando estivem com relatos de sintomas e possibilidade decontaminção ${ }^{13,14}$.

\section{CONCLUSÃO}

Concluímos que, a atuação da enfermagem aos profissionais da saúde na pandemia é de extrema importância. Durante os atendimentos de enfermagem efetuados na coleta de exames para o diagnóstico da COVID-19, demonstramos as experiências apresentadas pelos pacientes, os profissionais da saúde sintomáticos durante sua atuação na linha de frente da pandemia da COVID-19.

Os profissionais da saúde relataram que as instituições de saúde muitas vezes deixam os trabalhadores desamparados acerca dos EPI apropriados a assistência a pacientes com suspeitas ou caso confirmado da COVID-19.

Durante os atendimentos, foi perceptível a desatualização dos profissionais da saúde em relação aos tipos de testes disponíveis e de modo consequente, seu correto manejo, sabendo disso, os profissionais de enfermagem atuaram diretamente na educação continuada em cada atendimento. Além disso, os profissionais da saúde enfatizaram a desassistência das instituições de saúde acerca dos diagnósticos dos empregados para a COVID-19.

Mediante o cenário que estamos vivenciando, concluímos que a experiência apresentada reflete a vulnerabilidade dos profissionais da saúde, por intermédio da atuação da enfermagem durante a pandemia da COVID-19. Contudo, este estudo evidencia a importância da atualização profissional da saúde acerca do contexto da pandemia do novo coronavírus para que desta forma os profissionais da saúde consigam exigir os seus direitos, tais como o acesso aos EPIs.

Além disso, torna-se relevante abordagens e estratégicas de órgãos governamentais e de instituições de saúde acerca de capacitação para os profissionais da saúde e acesso aos equipamentos necessário para a saúde do trabalhador e saúde mental.

\section{Referências}

1.Chen Y, Liu Q, Guo Deyin. Emerging coronavirus: Genome structure, replication, and pathogenesis. J Med Viral, 418-423, 2020. Disponível em: https:// pesquisa.bvsalud.org/controlecancer/resource/pt/mdl-31967327

2.Wrapp D, et al. Cryo-EM structure of the 2019-nCoV spike in the prefusion conformation. Science 367, 1260-1263, February 19, 2020. Disponível em: https://science.sciencemag.org/content/367/6483/1260

3. Ministério da Saúde. Recomendações de proteção aos trabalhadores dos serviços de saúde no atendimento de COVID-19 e outras síndromes gripais. Ministério da Saúde. 2020;1-37.

4. Agência Nacional de Vigilância Sanitária. Nota técnica GVIMS/GGTES/ ANVISA $n^{\circ}$ 07/2020 orientações para prevenção e vigilância epidemiológica das infecções por sars-cov-2 (covid-19) dentro dos serviços de saúde - Agência Nacional De Vigilância Sanitária - Anvisa. 2020. p. 1-50.

5. Habibzadeh P , Stoneman EK. The Novel Coronavirus: A Bird's Eye View. Int J Occup Environ Med ;11:65-71. Vol 11, Num 2; April, 2020

6 . $\mathrm{LI} \mathrm{Z}$, et al. Vicarious traumatization in the general public, members, and non-members of medical teams aiding in COVID-19 control. Brain Behav, 2020.

7. Dias DVM de CH, Carneiro DM, Dra. Cláudia Fernanda de Lacerda Vidal, Corradi DM de FD Ben, Brandão DD. Orientações sobre Diagnóstico, Tratamento e Isolamento de Pacientes Este documento foi desenvolvido com o objetivo de apresentar um compilado dos conhecimentos adquiridos até o momento, que possam orientar sobre a abordagem diagnóstica de $\mathrm{CO}$ VID-19, bem. Grupo Força Colaborativa Covid-19 Brasil. 2020. p. 1-76.

8. Agência Nacional de Vigilância Sanitária. Nota Técnica No 04/2020
GVIMS / GGTES/ANVISA. Orientações para Serviços de Saúde: Medidas de Prevenção e Controle que Devem Ser Adotadas Durante a Assistência aos Casos Suspeitos ou Confirmados de Infecção pelo novo coronavírus (2019nCoV). Agência Nacional De Vigilância Sanitária - Anvisa. 2020. p. 1-92. 9. Ministério da Saúde. Protocolo de Manejo Clínico para o Novo Coronavírus (2019-nCoV). Ministério da Saúde. 2020. p. 1-32.

10. WHO. World Health Organization. Rational use of personal protective equipment for coronavirus disease 2019 (COVID-19) and considerations during severe shortages [Internet]. Who. 2020. p. 1-28. Available from: https:// apps.who.int/iris/handle/10665/331695

11. Mandrola J. CoViD-19 e dispositivi di protezione individuale: qualcuno di noi morirà per la loro carenza. Recent Prog Med [Internet]. 2020;111(4):183. Available from: https://dx.doi.org/10.1701/3347.33175

12. Delgado D, Quintana FW, Perez G, Liprandi AS, Ponte-Negretti C, Mendoza I, et al. Personal safety during the covid-19 pandemic: Realities and perspectives of healthcare workers in Latin America. Int J Environ Res Public Health. 2020; 17(8):1-8.

13. WHO. Coronavirus disease (COVID-19): outbreak: rights, roles and responsibilities of health workers, including key considerations for occupational safety and health. 2020. Disponivel em: https://www.who.int/docs/default-source/coronaviruse/who-rights-roles-respon-hw-covid-19.pdf?sfvrsn=bcabd401_0

14. Ministério da Saúde. Diretrizes para diagnóstico e tratamento da COVID-19. Ministério da Saúde. 2020. p. 1-397. 